\title{
Micro-XRF Trace Element Quantification in Calcite: a Contribution to White Marble Provenance Determination
}

\author{
M. Serra, ${ }^{*}$ A. Borghi, ${ }^{*}$ R. Cabella, ${ }^{* *}$ L.M. Gallo, ${ }^{* * *}$ and G. Vaggelli, ${ }^{* * * *}$ \\ * Dipartimento di Scienze Mineralogiche e Petrologiche, Facoltà di Scienze Matematiche Fisiche e Naturali, \\ Università degli Studi di Torino, Via Valperga Caluso 35, 10125, Torino (TO), Italia \\ ** Dipartimento per lo Studio del Territorio e delle sue Risorse, Facoltà di Scienze Matematiche Fisiche e \\ Naturali, Università degli Studi di Genova, Corso Europa 26, 16132 Genova (GE), Italia \\ *** Museo Regionale di Scienze Naturali di Torino, Sezione di Mineralogia, Petrografia e Geologia, Via Giolitti \\ 36, 10123 Torino (TO), Italia \\ **** CNR, Istituto di Geoscienze e Georisorse, Sezione di Torino, Via Valperga Caluso 35, 10125, Torino (TO), \\ Italia
}

In the last few decades marble provenance identification has represented a focal concern for archaeometric researches, leading to the creation of extensive databases based on the combined results of different geological and physico-chemical methods [e.g. 1,2]. Even though isotope geochemistry seemed to give the most discriminant results [e.g. 3], the progressive increasing of the database and the consequent overlapping of the characteristic fields pointed out the need of developing multi-method strategies [e.g. 4, 5].

The methodological approach presented here combines petrographic and $\mu$-XRF geochemical data acquired on a set of 320 reference samples from 20 different Mediterranean quarrying sites.

Main goal of the research was to evaluate the effective discriminant capability of a new micro-analytical approach based on trace element quantification with $\mu$-XRF Eagle III-XPL (Röntgenanalytik Messtechnik GmbH, Germany) non-destructive instrument. Poly-capillary lenses $(30 \mu \mathrm{m})$ were used to collimate the microbeam at the sample surface. Single spot analyses on calcite grains gave reproducible results within the same quarry and allowed overcoming the problem of the considerable variations of solution-based ICP-MS analyses.

Preliminary results on Alpine and Apuan Italian marbles [6] encouraged the creation of a wider database which took advantage of the availability of different private and academic collections coming from the University of Turin, Genoa and Florence and from the Regional Museum of Natural Science of Turin. The whole set of samples led to the acquisition of original data and allowed quantitative testing the discriminant power of the chosen variables though different samples of the same quarry and in different quarries of the same district. Moreover, it contributed to the scientific valorization of valuable Cultural Heritage.

The choice of the varieties to be included in the database was determined by the historic and economic importance of each specific quarrying site over time. They correspond to the well-known Greek marbles from Aegean Islands (Naxos, Paros, Thasos, Tinos) and Attica (Hymettos, Pentelikon), Turkish islands (Proconnesos), Aegean coast (Ephesus) and Western Anatolia (Afyon, Altintaş, Aphrodisias). Spain was represented by Macael marble, while Italian Apuan varieties (Carrara, Saravezza) were analyzed together with Alpine marbles (Lasa, Crevoladossola, Prali, Ornavasso, Brossasco, Chianocco, Pont Canavese). 
Calcite compositional data were acquired optimizing analytical conditions for different energetic intervals and the statistical error was evaluated by amorphous and crystalline standards (NIST SRM 610 - 612, Standard Carrara Marble M43). The referred averages for NIST SRM trace elements standards (50 and $500 \mathrm{ppm}$ ) [7], were used for $\mu$-XRF calibration. Applying $40 \mathrm{kV}, 1 \mathrm{~mA}$, a Ti primary filter $(25 \mu \mathrm{m}$ thick), the statistical intensity error percentage from $\mathrm{Mn}$ to $\mathrm{Nb}$ was $<5 \%$ at $50 \mathrm{ppm}$ concentration (live time of $1000 \mathrm{~s}$ ) and $<3 \%$ at $500 \mathrm{ppm}$ (live time $1000 \mathrm{~s}) . \mathrm{Mg}$ concentration was acquired for $1000 \mathrm{~s}$ using $10 \mathrm{kV}, 1 \mathrm{~mA}$ on unfiltered primary beam. Statistical intensity error, in this case, was below $2 \%$ at $500 \mathrm{ppm}$ certified concentration.

Each spot analysis was repeated three times varying the orientation of the crystals in the sample plane. The object of rotating the sample in its analysis plane was to change the Bragg conditions and randomize the location of diffraction peaks. The final X-ray spectra result from $0^{\circ}, 72^{\circ}$ and $144^{\circ}$ rotations after removal of diffraction peaks. Calcite compositional data were cross-checked and critically compared to SEM-EDS, ICP-AES and ICP-MS independent analyses on the same samples.

Factor and principal component statistical analysis drove the selection of the experimental variables, taking into account petrographic and geochemical evidences. Continuous variables matched micro-XRF calcite composition, expressed as ppm of the most discriminant minor and trace elements: $\mathrm{Mg}, \mathrm{Mn}, \mathrm{Fe}, \mathrm{Zn}$ and Sr. Petrographic variables corresponded to thin section optical microscope observations. In particular maximum grain size, grain boundary shape, texture and shape of the crystals were considered.

The acquisition of quantitative profiles from the surface to the bulk of altered marbles helped evaluating the effects of biogeochemical weathering on the elemental composition. In agreement to previous considerations [8], the results obtained on natural samples suggest a net decrease in Sr concentration associated to a contextual enrichment in $\mathrm{Fe}$ and $\mathrm{Mn}$ at the marble surface. These preliminary data confirm the fundamental importance of a careful sampling in the study of ancient stone artifacts.

Chemometric methods were used for data mining and development of proper grouping procedures. The final cross-validated models were successfully used in different case-studies, including byzantine marbles from western Liguria and medieval coat of arms from the Racconigi residence of the Royal House of Savoy.

\section{References}

[1] D. Attanasio et al., The Isotopic Signature of Classical Marbles, L'Erma di Bretschneider, Roma, 2006

[2] K. J. Matthews, Archaeometry 39, 2 (1997) 321-332.

[3] Craig, H., and Craig, V., Science, 176 (1972) 401-403

[4] J. Herrmann et al. (eds.), Interdisciplinary Studies on Ancient Stone, ASMOSIA V (2002) 420

[5] A. Ebert et al., Archaeometry 52, 2 (2010) 209-228.

[6] M. Serra, AIAr VI Programma e abstract (2010) 44.

[7] Pearce et al., Geostandard Newsletter 21, 1 (1997) 115-144.

[8] K. Polikreti, Archaeometry 49, 4 (2007) 603-619.

[9] This work was financially supported by Ministero dell'Università e della Ricerca Scientifica e Tecnologica (M.U.R.S.T.). Centro Interdipartimentale "G. Scansetti” is thanked for $\mu$-XRF allowing access. 